\title{
Rework Causation: Emergent Theorectical Insights and Implications for Research
}

.

\author{
Peter E.D. Love ${ }^{1}$, David J. Edwards² ${ }^{2}$ Jim Smith $^{3}$ and Jane Mathews ${ }^{4}$
}

\begin{abstract}
Rework is a chronic problem in construction and engineering projects. A plethora of studies examining the nature of rework have been undertaken since Burati et al. (1992) examined quality deviations. Early studies initially focused on identifying the causal factors and costs of rework to quantify the severity of the problem. These initial studies recognized that because rework causes are both interdependent and complex, techniques such as Cognitive Mapping and System Dynamics were introduced to model this phenomena. These models provided invaluable insight needed to stimulate theory development - yet despite this advance in knoweldge, rework remains a pervasive issue. Several factors have have exacerbated the prevailing causal ambiguity, for example, the epistemological underpinning used to construct the nature of causes and the subsequent use of analysis tools and techniques. Evidence of this ambiguity is presented in recent studies that have failed to acknowledge the interdependency of rework causes. Indeed, research has regressed to identifying causality of singular nature using one-dimensional tools such as questionnaire surveys. Consequently, such research continues to stymie progress toward reducing and containing rework and a moratorium for such approaches to examine rework causation is suggested. With this in mind, insights into the extant rework literature and causation philosophy are examined and recommendations to improve the understanding necessary to establish a theory for rework causality are proposed.
\end{abstract}

Keywords: Causal ambiguity, epistemology, questionnaire surveys, rework, causation theory

\footnotetext{
${ }^{1}$ DS.c, Ph.D., John Curtin Distinguished Professor, Department of Civil Engineering, Curtin University, Perth, GPO Box U1987, Perth, WA, Australia, Email: plove@iinet.net.au

${ }^{2}$ Ph.D., Professor, Birmingham City Business School, Birmingham City University, Perry Bar B42 2SU, Birmingham, United Kingdom, Email: david.edwards@bcu.ac.uk

${ }^{3}$ Ph.D Professor, Institute of Sustainable Development and Architecture, Bond University, Gold Coast, QLD 4229, Australia, Email: jismith@bond.edu.au

${ }^{4}$ Ph.D, Associate Professor, Department of Construction Management, Curtin University, Perth, GPO Box U1987, Perth, WA, Australia, Email: jane.matthews@curtin.edu.au
} 
Introduction

\begin{abstract}
"We think of a cause as something that makes a difference, and the difference it makes must be a difference from what would have happened without it. Had it been absent, its effects - some of them, at least, and usually all — would have been absent as well.” (Lewis, 1973b, p.161)
\end{abstract}

Rework remains a chronic problem in construction and engineering projects (e.g. Burati et al., 1992; Barber et al., 2000; Li and Taylor, 2014). Various definitions of rework have been propagated, which has resulted in significant discrepancies in reported costs. For example, Rogge et al. (2001) defined rework as: "activities in the field to be done more than once in the field or activities which remove work previously installed as part of the project." Love (2002a) defined it as the: "unnecessary effort of re-doing a process or activity that was implemented incorrectly the first time, which accommodates design and construction errors, omission and changes, which may arise." Conversely, Robinson-Fayek et al. (2004) refers to rework as the: "total direct cost of redoing work in the field regardless of initiating cause." Robinson-Fayek et al. (2004) specifically state that their definition excludes change orders and errors due to off-site manufacture, which are not considered as rework. Such differences have been further compounded by the methods used to quantify rework costs, and naturally this also impacts upon determining its causal nature (Love and Sing, 2013). For example, case study based-research that relied upon close interaction with contractors and establishment of a formal measurement system revealed that direct rework costs during construction ranged from $2 \%$ to $5 \%$ of contract value (e.g. Love and Li, 2000; RobinsonFayek et al., 2004; Kakitahi et al., 2014; Taggart et al., 2014). When indirect costs of are considered (Barber et al., 2000) rework increased to $16 \%$ and $23 \%$ of contract value. These estimates included an allowance for the cost of delays that were incurred. If these were removed, then rework costs would have equated to $3.6 \%$ and $6.6 \%$ of contract value. Love (2002b) suggested that indirect rework can have a 'multiplier effect' of up to six times the actual (direct) cost of rectification. Case study research undoubtedly has its merits however, the number of cases presented in studies has been limited and thus only stimulated research to be repeatedly exploratory instead of being explanatory, which is essential for developing theory of rework causation in construction (Love et al., 2002)

With tight profit margins and the need for higher productivity levels, clients and their project teams cannot ignore rework as ultimately business survival is jeopardized. Despite considerable research undertaken to date, there is a clear paucity of evidence to confirm that rework is being reduced or contained in projects despite similar costs and causes being identified more than 25 years ago (e.g. Aiyetan, 2013; Hwang et al., 2014; Kakitahi et al., 2014; Taggart et al., 2014; Jingmond and Ågren, 2015). Building upon knowledge accrued to date, this paper provides insights into rework causation and specifically calls for a moratorium for future studies to provide a contextual backdrop via which to better understand the rework connundrum. The research culminates with the philosophical stance that past research may have maligned our ability to delevop a deeper and 
richer awareness as to 'why' and 'how' rework arises in projects; this in turn has impeded the development of a 'theory' for its causation.

\section{Rework Causation}

A plethora of rework related studies have focused on identifying specific causation factors and how they influence the cost and schedule performance of projects (e.g. Love and Li, 2000; Love et al., 2004; Love and Edwards, 2004; Hwang et al., 2009; Love et al., 2009a,b: Aiyetan, 2013; Hwang et al., 2014; Kakitahi et al., 2014). For example, Ye et al. (2014) concluded that:

"Because the majority of rework causes identified in this study confirm those found in previous work, the findings from this study consolidate existing knowledge with new evidence from China. New causes, such as contract management, active reworks, and scope management, are also identified, which helps expand existing knowledge for the global construction community"

A closer examination of the literature by Ye et al. (ibid) reveals that the purported 'new' causes were identified in previous studies more than decade ago (e.g. Rodrigues and Bowers, 1996; Love et al., 1999; Josephson et al., 2002; Love and Edwards, 2004). Similarly, the work of Hwang et al. (2014) and Kakitahi et al. (2014) were previously reported upon by Burati et al. (1992) and a abundance of other studies conducted in the 1990s (e.g. Abdul-Rahman, 1995; CIDA, 1995; Love et al., 1999). Within hindsight, the rework related research of Ye et al. (2014), Hwang et al. (2014), Kakitahi et al. (2014), Taggart et al. (2014) and Jingmondand Ågren (2015) has either unwittingly regressed knowledge to historical milestones already firmly established within the extant literature or has been subject to conscienous-raising. Ye et al. (2014) provide an exemplar to support this assertion when they simply list rework causes derived from a questionnaire and then use 'Factor Analysis' from a heterogeneous sample to add statistical rigor to determine a commonality of groupings for variables without defining the context regards how rework arose in the projects they sampled. Love et al. (2009a), undertook similar work but produced a Structural Equation Model without providing the underlying knowledge needed to be able reduce and contain rework (Love et al., 2015a).

Notably, seeking opinions about rework causes from heterogeneous samples through questionnaires is considered to provide uncertain results (e.g. Love and Edwards, 2004; Ye et al., 2014). This is because respondents rarely view the same event at the same time and therefore, inconsistencies arise with the testimonies/ responses of other participants who are involved with the same project. Ye et al. (2014), for example, identify "poor communication path of project instructions" as a cause of rework, but this observation simplifies the complexity associated with how people interpret information. In explaining this complexity, Busby (2001) suggests that problems do not arise because $\mathrm{X}$ does not communicate $\mathrm{Z}$ to $\mathrm{Y}$, but the way $\mathrm{Y}$ interprets $\mathrm{Z}$ in light 
of some prior experience (or lack of), which $\mathrm{X}$ does not know about. Thus, $\mathrm{X}$ fails to make allowances for $\mathrm{Z}$, and $\mathrm{Y}$ does not realize $\mathrm{X}$ does this as $\mathrm{Y}$ thinks that both their experiences are representative. In short, improving communication practices via technology or using Building Information Modeling (BIM) will not reduce the incidence of rework per se. Fundamentally, work processes, policies, procedures and behaviours need to change in concert if rework is to be reduced (Love et al., 2011a). Suggesting that "unclear and ambiguous project process management" and "poor quality of construction technologies used" result in rework (Ye et al., 2014) are 'conditional' not 'casuality' statements, especially as an infinite number of possible outcomes may arise from these declarations. An important distinction is that statements of causality require an antecedent or coincidence with the consequent events, whereas conditional statements do not require this temporal order. Thus, the epistemological underpinning used to draw conclusions of causality is misplaced in this instance.

Several case studies have also derived 'singular' causal factors (c.f. Love and Li, 2000; Josephson et al., 2002). While such studies have attempted to provide a context to explain 'why' and 'how' rework arose, the views of those participants involved in the chain of events that lead to its occurrence are generally limited to specific points in time. Thus, the determination of causation is narrowly defined and potentially leads to bias being reported. Construction researchers have defined the 'root cause' of rework as a point in a causal chain which facilitates intervention that changes performance and/ or prevents an undesirable outcome. However, 'the root cause' often merely represents the place in a point of time where a researcher decided to complete their investigation (Dekker, 2002; Hollnagel, 2004; Dekker, 2006). Consequently, sub-optimal reworkmitigation solutions have been identified (Love et al., 2011a). This arrogant certainty of science has allowed notions to be constructed about rework yet the means of actively reducing it alludes the scientific community (Love et al., 2015b,c).

\section{Human Error and Rework}

Rework predominately arises due to human error, such as mistakes (rule or knowledge based), slips and lapses of attention, and acts of omission and commission (Love and Josephson, 2004; Love et al., 2011a; Love and Li, 2000; Taggart et al., 2014). However, many rework studies have not consulted the error literature to understand why people performed the acts that lead to their occurrence and how they could have prevented the event from occurring (e.g. Ye et al., 2014; Kakitahi et al., 2014; Jingmond and Ågren, 2015).

Observations of the conditions contributing to human error are drawn from Love et al.'s (e.g. 2009b; 2012a,b) phenomenological research and are presented in Table 1. Two observations are repeatedly identified by Love and his colleagues; namely: (1) people breaking rules because of the belief that such augments efficiency, which is akin to procedural violations and omission errors; 
and (2) organizations breaching specified work practices and procedures. When combined with project delivery strategies (that are risk averse for clients and place emphasis on competitive tendering), the propensity for risk-taking by consultants and contractors increases in order to maximize both their margins (Love et al., 2011b).

Ford and Sterman (2003) provide an invaluable insight into what transpires when rework negatively influences an organization's bottom-line and suggest that employees may conceal it to avoid informing managers of 'bad news' and/ or present information that does not adhere to their beliefs. According to Ford and Sterman (2003) the practice of hiding mistakes is institutionalized in many organizations and is akin to an error or omission. In fact, Roth and Kliener (1996) observed a cultural mandate within engineering organizations of not informing people about problems unless solutions are forthcoming. Thus, concealing problems becomes standard practice (Ford and Sterman, 2003) which results in a 'Prisoner's Dilemma'. This wall of silence enables project team members to abrogate their direct responsibility thereby preventing any form of reprimand from their immediate manager. Regards the Prisoner's Dilemma scenario, managers may question team members about project's progress without being provided with all the necessary information. Team members can: "cooperate with one another by concealing the problems that they know exist, or defect by revealing" the issues that need to be addressed to the project manager (Ford and Sterman, 2003:p.215). If the project team members cooperate by concealing known problems, project costs and schedule will remain the same and they avoid blame. Revealing problems caused by others, may increase project cost and could led to schedule slippage, giving them the opportunity to attend to these issues. However, most people are reluctant to become a 'whistleblower', given the the acrimony attached to such activity.

Table 1. Observations of the conditions contributing to human error

\section{Observation}

- No one had a clue, they had different understandings of the same event

- People filter out most of the information around them

\section{Comment}

Parties involved in a rework event all had differing opinions as to 'how' and 'why' it occurred, as demonstrated in the example presented in Table 1. Basically, what may be apparent to one individual will differ to another. People select information to make sense of a situation as they perceive it to occur. It is deemed to be easier for people to seek confirming evidence for their current undertstanding than to test it and risk having to invest in significant time and effort in devising another explanation.

In this instance, people are only interested in the information required to undertake their task. If information is missing, then they may request it, though this will often depend on the 'level' 
that is required. People possess a hierarchy of mental filters and thus select the information that best suits their needs.

- Cultural differences increase the likelihood of different interpretations of the same event

- Problems arise when the goals of people in the same organization start to diverge

- People break rules to make work more efficient

- People's decisions are a trade-off between the available information and the available time

- People make mistakes. Organizations make it possible for the mistakes to be really serious
Differing parties involved in a delivery of a project have differing goals and objectives which are crafted as a result of their organization's culture. What is considered relevant to one person may not be relevant to another as a result of the task they are undertaking and thus socio-political and organizational pressures can shape their perceptions and memory of an event. Organizations involved with delivering construction projects tend to have differing goals. A lack of understanding of each participating organizations roles and capabilities leads to divergence and problems arising.

Time and cost are innate features of construction projects. Thus, within this context people make trade-offs between efficiency and thoroughness, which is guided by the experience and training a person has been given.

People often do not have enough time to complete their tasks. As a result, they rely on an alternative approach to produce the best decisions using the available nformation within the time they have. In addition, within construction there is a great deal of uncertainty and complete information is often not made available.

Inadequate time, design, staffing and the lack of good management that contribute to errors may combine to make a situation even worse. For example, building failure, which may result in injury or even deaths.
166

For reasons of self-preservation, it is better to allow other project team members to be blamed for the cost and schedule overruns that may occur. Should all team members reveal the problems known, project costs increase and the schedule slips, but all are apportioned blame from management - a lose-lose outcome for all. Refusing to admit to a negative outcome and to continue a course of action can contribute to rework and is referred to 'defensive avoidance' (Love et al., 1999; Janis and Mann, 1977). Shaw (1981) provides several explanations for this phenomenon. First, people pursue a course of action in spite of negative feedback; this suggests that people value tenacity, or perseverance, as they generally admire those who stick to their principles (Shaw, 1981). Second, people will forsake a more rational approach to difficult decision situations out of the concern with establishing consistency, a valued characteristic.

\section{Systemic Approach}

The identification of singular causes (which in most cases only describe the proximal causes i.e. those nearest in time to the event) is counterintuitive, as rework causation can only be understood 
181 by considering the whole project system holistically and how variables dynamically inter-react

182 (Taylor and Ford, 2006; Aljassmi and Han, 2013; Han et al., 2013; Li and Taylor, 2014). Causality 183 governs the relationship between events and its formalization enables a system to be constructed 184 that has a set of observable causal variables (Goodman et al., 2011). Techniques such as Cognitive 185 Mapping (CM) and System Dynamics (SD) have been used to observe the behavior and determine 186 the interdependency of causal rework events. However, these techniques have limitations and 187 therefore an alternative epistemological underpinning to examining this phenomenon is proposed 188 in this paper. Prior to introducing this alternative agenda, systemic approaches presented in the 189 literature are first examined.

\section{Cognitive Mapping}

192 Cognitive mapping (CM) enables people to process their environment, solve problems and use 193 memory. It is derived from Kelly's (1955) theory of personal constructs, which suggests that: "we make sense of the world in order to predict how, ceteris paribus, the world will be in the future and to decide how we might act or intervene to achieve what we prefer within that world: a predict and control view of problem solving " (Ackermann et al., 1992: p.1). Operations Researchers have extensively used this qualitative technique as a tool to construct, organize and analyse data related to project performance and disputes by enabling a structured account of the problem to be created (e.g. Ackermann et al., 1997; Williams et al., 2003; Ackermann and Eden, 2005; Ackermann, 2012). In addressing issues associated with project performance and disputes, rework was identified as major contributor and has been accordingly mapped. However, creating a cognitive map for rework is a time-consuming process for the person charged with undertaking the task of comprehending information presented, typically in an interview or focus group format, while having to simultaneously remember the guidelines required to produce the influence diagram. As a result, salient issues that contributed to events that lead to the rework event may be overlooked.

While CM provides a graphical structure for addressing the 'messiness' associated with understanding rework causation, a number of factors such as cognitive perspectives, cognitive reference points, and the specific rotation to a frame of reference, can distort the memory and judgment of the person being interviewed (Tversky, 1993). Hence, when utilizing CM it is important to obtain multiple views that can explain the rework events occurrence (Tversky, 1993). Addressing this issue may create an overly complicated diagram that is difficult to understand, particularly for practitioners who may have limited knowledge of the concept. Notwithstanding this limitation, $\mathrm{CM}$ is a useful tool for understanding the complexity associated with rework causation (Jingmond and Ågren, 2015).

\section{System Dynamics}


System dynamics (SD) has been used extensively to model the dynamic and complex nature of projects, particularly errors and rework (e.g. Lynies and Ford, 2007; Han et al., 2013). Both the qualitative (e.g. influence and causal loop diagrams (CLD)) and quantitative (e.g. stock-flow and simulation) dimensions of SD have been utilised to develop models that explain the behavior and impact of rework on project performance (Ackermann et al., 1997). Copper's (1993a; b) influential work provided the platform for examining the systemic nature of rework and is core to understanding how SD is applied to projects. The 'Rework Cycle' provides a description of workflow that incorporates rework and undiscovered rework. Work rate is determined by staff skills, productivity and availability, and as project time advances, the amount of work remaining reduces. Work is then completed to a specified standard or becomes undiscovered rework that contains errors that have yet to be identified but are perceived to have been undertaken. Latent errors are often not immediately identifiable and only transpire after a period of incubation in the system. After some time these errors are eventually detected, or they arise in due course and rework is identified, which increases the amount of work to be undertaken (Cooper, 1993; Rodrigues and Williams, 1998). Akin to CM, CLDs have invariably been based upon interview data and thus a participant's memory and judgment is predominantely relied upon to give an account of what transpired. Moreover, conditional statements are used to create an association or determine an influence and while plausible, the issue of causation remains an unaddressed issue. A lack of real life industry specific data (such as design errors) to create and simulate the dynamic nature of rework using stock-flows also diminishes the accuracy, validity and reliability of SD models (Tombesi, 2000).

\section{Context: Judgement and Counterfactual Alternatives}

When constructing graphical causal diagrams, it should be noted that people's thoughts about the causal relationships between rework events influence their judgments of the plausibility of 'counterfactual alternatives'. Equally, their 'counterfactual thinking' about how a situation could have turned out differently can change their judgments of the causal role of events as well as those responsible (Roese and Olson, 1995; Roese, 1997). Yet according to Bryne (2005) identifying the cause of an event and the counterfactual thoughtdo not always correspond. This is due to participants in projects distinguishing between the various type of causes and making different inferences from dissimilar causes (Miller and Johnson-Laird, 1976; Love et al., 2015a). In addressing this shortcoming, a contractor, who is preparing a rework claim may sieve through the available evidence and look for fragments of information that seem to point to a common cause in developing a priori explanation. While this approach is common, it is also problematic as (Dekker, 2006) notes:

- $\quad$ details that are relevant to explaining the actions and behaviors of people can be overlooked; and 
- the information collated is meaningless outside the context where it originated. Invariably the pieces of information obtained are combined with those of a similar nature, though it may have its own context and raison d'etre. In fact, when the data was produced it may be divorced from other fragments of information which it has been combined with.

Taking information out of context by selecting and combining it together in hindsight or micromatching it with a view that the contractor knows now to be true is misleading as the original context and meaning becomes redundant and a new sense adopted. The construction of a rework 'cause' is dependent upon the experience and views of those who are involved with the event. For example, Love et al. (1999) sought to explain 'why' and 'how' the pitch of a structural steel framed roof for a residential building failed building regulations and subsequently had to be re-designed and re-engineered. Drawing from the vignette presented in Love et al. (1999), the differing points of view as to the contributing causes of rework, from the perspective of the contractor and architect, are presented in Table 2.

Table 2. Differing points of view: Contributing causes for the same rework event

\begin{tabular}{l|l}
\hline \multicolumn{1}{c|}{ Contractor } & \multicolumn{1}{c}{ Architect } \\
\hline $\begin{array}{l}\text { Errors in contract documentation provided by the } \\
\text { architect }\end{array}$ & $\bullet \begin{array}{l}\text { Limited time provided by the client to document } \\
\text { the design }\end{array}$ \\
$\begin{array}{l}\text { Inadequate design audits and design review by the } \\
\text { architect and structural engineer }\end{array}$ & $\begin{array}{l}\text { Structural engineer's design did not 'actively' } \\
\text { coordinate and integrate with the architectural } \\
\text { design } \\
\text { - Inadequate use of technology to coordinate the } \\
\text { architectural and engineering design }\end{array}$ \\
$\begin{array}{l}\text { Over-reliance by the architect to ensure the } \\
\text { contractor would identify errors prior to } \\
\text { construction }\end{array}$ & $\begin{array}{l}\text { Worchitectural and structural engineering drawings } \\
\text { Contractor did not plan and coordinate works on } \\
\text { site with other trades }\end{array}$ \\
\hline
\end{tabular}
Unsurprisingly, the factors identified by both parties contributed to the rework that materialized but in this instance, the parties may have selectively chosen those that have contributed to the event. Invariably socio-political, cultural and organizational pressures rather than the context within which they arose may have driven their selection in this instance. Considering this scenario, Dekker (2006) suggested that a: "cause is not something you find. Cause is something you construct. How you construct it and from what evidence, where you look, what you look for, who you talk to, what you have seen before, and likely on whom you work for."

\section{Understanding of Causation: Issues and Challenges}


Studies examining rework causation have not been based upon a theory. The establishment of relationships have been based upon people's innate ability to infer the causal structure of a project system is derived from the individual's organisational culture and relationships. As for any inductive task, causal inference is an ill-posed problem: the data that is viewed undermines the true causal structure (Tenebaum and Griffth, 2003). This is a statistician's dilemma as a 'correlation does not imply causation'; a mere association exists (ibid). The assumption, that correlation proves causation, is considered to be a 'questionable cause fallacy' whereby two events occurring together are taken to have a cause-and-effect relationship (Cavender and Kahne, 2010). Essentially, a causal connection is assumed without proof. This fallacy is also known as cum hoc ergo propter hoc, (i.e. "with this, therefore because of this", and 'false cause' A similar fallacy whereby an event that follows another is necessarily a consequence of the first event, is described by Damer (1995) as post hoc ergo propter hoc (i.e. "after this, therefore because of this").

A range of causality theories are categorized according to the way they address key questions (e.g. Russell, 1913; Salmon, 1998; Pearl, 2000; Hitchcock, 2012; Williamson, 2009). One question often posed is 'are the causal relata single-case or generic'? A philosophical theory of causality might hold that a cause or effect concerns a single occasion and so either obtains or fails to obtain, for example, an contractor's presentation of a claim to a client may cause them to a great deal of angst. Alternatively, it may hold that causes and effects can obtain and fail to obtain on different occasions: errors cause rework. In the former case, cause and effects are called single-case, particular or token-level and for the latter, they are generic, repeatedly instantiable or type-level (Williamson 2009). Another perspective of causation examines the causal relata at the individual or population level (ibid). At the population-level, a cause or effect concerns a group of individuals, for example, an increase in the number of change-orders in a project causes a reduction in the project team's morale. The individual-level cause or effect concerns only one person at a time, for example, long working hours causes stress. According to Williamson (ibid): "such causal relata occur in our causal claims, so any theory that considers one kind to the exclusion of others provides only a partial account of causality.". With this in mind, the causal relata of a rework event should then be determined from the perspectives of the individual, organization and project through an epistemological lens that accommodates varying perspectives to provide a thorough and balanced account of its causation.

Several questions have also been raised concerning the causal relationship itself. For example, "is causality some kind of physical connection between cause and effect?" or is "it purely mental in the sense that it is a feature of some individual's epistemic state?" (Williamson, 2006a,b; Williamson, 2009). Other questions seek to address "whether causal relationships are objective?" or "does the theory in question attempt to understand actual or potential causality"? In the former case, if two agents disagree to causal relationships, then at least one of them must be wrong or is it subjective, admitting a degree of personal choice? (Williamson, 2009). In addressing the latter, 
the general case is referred to as potential or possible causation, while the factual is called actual causation. Such questions are pivotal to the on-going discourse about the philosophical theory of causality.

A prominent approach to the study of causation has been to analyze it in terms of counterfactual conditionals (Paul, 2009); these represent a subjunctive conditional sentence, whose antecedent is contrary-to-fact (Hitchcock, 2012). For example "if a structural engineer had not specified reinforcement in concrete column, the building would have not collapsed." In the case of indeterministic outcomes, it may be appropriate to use probabilistic consequents: "if a structural engineer had not specified reinforcement in the concrete columns, the probability of the building not collapsing would be 0.1." Several studies have analyzed causation in terms of such probabilistic counterfactuals (e.g. Balke, 1995; Di Tillio et al., 2012; Schacter et al., 2013). However, counterfactuals refer to specific events at particular times, thus such theories of causation are singular in nature (Hitchcock, 2012). Consider the research of Ye et al.(1994) where the relationship of "poor communication path of project instructions" with rework, implicitly assumes causality in terms of counterfactual dependence of the effect on the cause: the cause is rendered counterfactually necessary for the effect (Love et al., 2012). Ye et al.'s (2014) presupposition infers that if poor communication had not occurred, then the rework would not have ensued. Causality can be defined by reference to a causal chain of counterfactually dependent events, where a sequence of events $(C, E, F, \ldots)$ is a chain of counterfactual dependence if $E$ counterfactually depends on $C, E$ counterfactually depends on $F$, and so on. Lewis (1973) asserted that "one event is a cause of another if and only if there exists a causal chain leading from the first to the second."

Various forms of counterfactual dependence have been adopted through the application of structural equations (e.g. Hitchcock, 2001) whereas limited studies have applied structural equations to examine the causal factors that contribute to rework (e.g. Love et al., 2009a). While such studies have provided a valuable contribution to understanding causal inferences through generalization, they have not provided a nomologically possible context. Such context would provide detail about how events unfold according to an underlying 'event theory', a set of background laws that define the outcome of events (Bell, 2004; Bell, 2007).

Figure 1 illustrates three nomologically different contexts where strategic misrepresentation $A$ and/ or optimism bias $C$ could give rise to a cost and/ or time overrun $E$. Each node represents an event. In this instance the occurrence of event $A$ or $C$ or both (at some implicit point in time) is the cause of the occurrence of event $E$ (at a later point in time). In the context of (a), $C$ and $D$ are proximate (as are $A$ and $D$ ), and $C$ and $E$ are remote. The occurrence of $C$ stimulates $D$, in this case a error, but inhibits $B$. The occurrence of $D$ then results in $E$ (i.e. rework). Besides, poor communication 
364

or inappropriate use of technology (Ye et al., 2014), pathogenic influences can give rise to $C$ and $A$, which can then trigger a series of events that result in $E$, rework (Love et al., 2012).

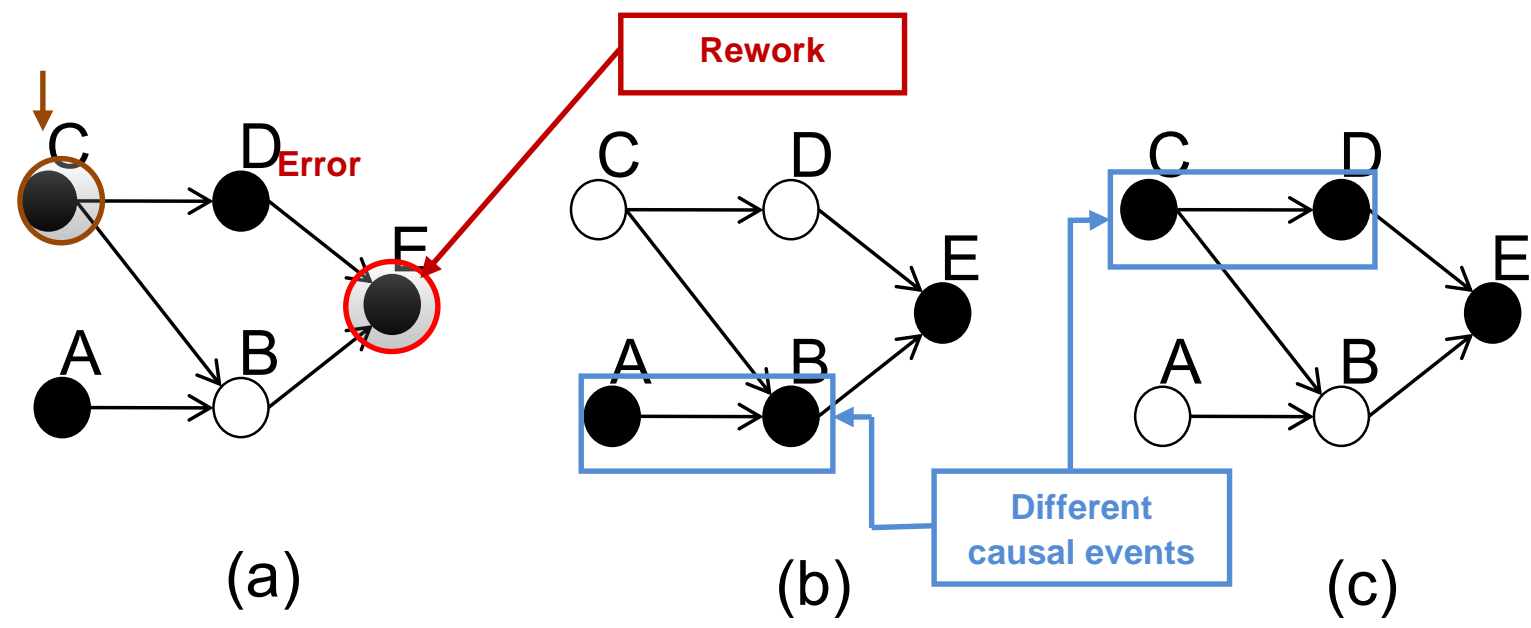

Adapted from Love et al. (2012b)

Figure 1. Nomologically different contexts each represent a different history

Nonetheless, it has been widely acknowledged that Lewis's theory (c.f. 1973) possesses several limitations (Menzies, 2014):

- Context-sensitivity - assumes that causation is an absolute whose nature does not vary from one context to the another. According to Lewis (1973) every event has an objective causal history consisting of a vast structure of events ordered by causal dependence. Hence, the human mind may select parts of the causal history for attention, perhaps different parts for different purposes of enquiry.

- $\quad$ Temporal asymmetry - assumes that time is fundamentally asymmetrical and there is a profound difference between the past and the future. Even if the notions of 'cause' and 'effect' are stripped of their directional bias, there is no evidence to suggest that the resulting causal relation is always exemplified asymmetrically in time. As a result, this difference is in no way indicative of a qualitative difference between the direction of time from earlier to later and vice versa.

- $\quad$ Transitivity - assumes chains of causal dependence to ensure causation is transitive; a key focus of counterfactuals. However, other possible events that do not have a direct cause are not addressed and therefore the issue of preemption is not addressed; and

- $\quad$ Preemption - is the root idea of causation. However, preemption does not explain how a preempting cause qualifies as a 'cause' when the effect does not causally depend on it. This 
is akin to the example presented above that discounted the notion of identifying a root cause for rework.

Menzies (1989) proffered a revision to Lewis's original theory (1973) by specifying attention to the continuous processes that are linked to causes and effects. This account is designed to handle cases of probability-raising from non-causes. Menzies (1996) concedes that this account remains problematic with certain types of pre-emption, and discarded it opting in favor of causation as a 'Concept of a Theoretical Entity', which treats it as an intrinsic relation between events. Thus, causation is defined by Menzies (1999) as: $C$ causes $E$ only if the intrinsic relation that typically accompanies causal dependence holds between $C$ and $E$. In dealing with preemption and additional problems that relate to causes that affect the time at which an event occurs, Noordhof (1999) developed a counterfactual probabilistic 'ceterbis parabis' theory where causes increase the probabilities of their effects. Building on this theory, Schaffer (2000) provides an explanation attending to causes that raise the probability of specific processes, rather than individual events, which have been motivated by the problems of preemption and probability-lowering causes.

To address the limitation of Lewis's (1973) theory, Lewis (2000) developed a 'Theory of Causation as Influence', although it does not accommodate deterministic causation and so does not address probabilistic pre-emption (Menzies, 2014). The central notion of the Lewis's (2000) 'Theory of Causation as Influence' is expressed as:

Where $C$ and $E$ are distinct events, $C$ influences $E$ if and only if there is a substantial range of $C 1, C 2, \ldots$ of different not-too-distant alterations of $C$ (including the actual alteration of $C$ ) and there is a range of $E 1, E 2, \ldots$ of alterations of $E$, at least some of which differ, such that if $C 1$ had occurred, $E 1$ would have occurred, and if $C 2$ had occurred, E2 would have occurred, and so on.

Where one event influences another, there is a pattern of counterfactual dependence of whether, when, and how upon whether, when, and how. In this instance causation is defined as ancestral relation whereby $C$ causes $E$ if and only if there is a chain of stepwise influence from $C$ to $E$. An ancestral relation is essentially a relation that stands to another as 'ancestor of' stands to 'parent of': an ancestor is a parent, or parent of a parent, and so on (Frege, 1879). However, the counterfactuals employed in Lewis's (2000) new theory do not state dependences of whether one event occurs on whether another event occurs. Instead, the counterfactuals state dependences of whether, when and how one event occurs on whether, when, and how another event occurs (Menzies, 2014). A key idea underpinning the formulation of these counterfactuals is that of an alteration of an event. This is an actualised or unactualised event that occurs at a marginally different time or in a dissimilar manner from the given event. Menzies (2014) states that an alteration is a fragile event that could not occur at a different time, or in a dissimilar manner without 
being an altered event. Lewis (2000) intended that the derived terminology be neutral on the issue of whether an alteration of an event is a version of the same event or a numerically different event. Notably, Lewis's (2000) new theory does accommodate cases of late as well as early pre-emption and therefore addresses, only to some extent, the issue of temporal asymmetry.

Through counterfactual thinking, people can reason how past changes affect the present and use such reasoning for cognitive tasks including social judgments, causal attribution, problem solving and learning (Roese, 1997; Byrne, 2002). Kahneman and Tversky (1982) suggest that people reason counterfactually by using a 'simulation heuristic', whereby events are altered in their mind (via recurrent ruminations) and a simulation run of how things would have gone otherwise, given these changes. A point to consider at this juncture is the 'conjuction fallacy' whereby people tend to assume specific conditions are more probable than a single general one (Kahneman and Tversky, 1983), rendering the complex task of assessing probabilities and predicting values to judgmental operations (Kahneman and Tversky, 1982). The subjective assessment of probability, often aligned with the use of qualitative diagrammatic aids such as CM and CLD to explain and examine rework causation are based on data with limited validity and therefore processed using heuristic rules and baises (Tversky and Kahneman, 1974).

The preceding discussion, illustrates that research examining rework causation is immature and lacks a robust theorectical foundation, which has therefore inhibited its reduction in construction and engineering projects. A significant amount of ambiguity prevails as to 'why' and 'how' rework occurs, its causal structure and ways in which to effectively contain and reduce its occurrence.

\section{Implications for Research}

Science aims to determine whether a set of axiomatic events or propositions can be accepted as true and validate the complex facts that establish causal relationships. According to Wold (1954) "the concept of causality is indepensablee and fundamental to all sciences.". Yet, in the pursuit of determing rework causation, a lack of a theorectical foundation or acknowledgement of complexity associated with its context, temporal asymmetry, transitiveness and preemptive nature has stagnated research and discernable improvements in practice. Future research should therefore place emphasis on establishing the counterfactual relationships between may exist between conditions. The notion of pathogenic influences providing the conditions for rework to materialize provides the basis for the use of counterfactual causation (Love et al., 2009b). The limitations of Lewis's (2000) theory, need to be considered together with the heuristic rules and biases that form an integral part of people's consciousness. In accommodating these issues, it is suggested that the development of theory based upon probabilistic causation and generalizations could provide underlying impetus to establish a setting for rework causation to be determined. Explicitly, to understand causal generalizations, there is a need to understand 'how' and 'why' participants in 
projects generalize about the rework they encounter and the circumstances that lead to its occurrence. Hence, the metaphysical task is to clarify the causal relevance of variables within homogeneous contexts (Hausmann, 2010). The works of Noordhof (1999), Williamson (2009), Hausmann (2010), and Di Tillio et al. (2012), provide fundamental building blocks for testing and developing a probabilistic theory of rework causation.

To generate generalizations for rework, however, it suggested that epistemological-based notion of sensemarking (Weick, 2001) can provide essential information needed to unearth probabilistic causation. Sensemaking is retrospective and grounded in identify construction and thus can be used to re-conceptualize and re-contextualize people's mechanistic and positivistic notions of the social reality that lead to rework (Love et al., 2015a). By gaining an understanding of the individual's role and views, plausibility extends beyond immediately observable phenomena; an attempt in this instance is made to fit together the evidence available to complete a puzzle despite not having some of the pieces. Thus, it is necessary to acquire multiple viewpoints from the causal chain. Obtaining such views will be a time-consuming, yet necessary validation process that will assist in the development of new theory. Without a valid and reliable theory of probabilistic causation, or variant thereof, for rework, empirical induction cannot provide researchers and practitioners with the needed rules to reject causal relationships and develop effect rework mitigation strategies.

\section{Conclusion}

This paper sought to highlight that the determination of rework causation research conducted to date, has had limited theoretical underpinning and is conceptually flawed. Having a theory to explain rework causation serves as a benchmark upon which the means of effectively mitigating its presence can be developed for construction and engineering projects. Relating to a theory of rework causation, may increases its ability to solve other problems in different times and places.

The comprehensive literature review conducted demonstrates that research into rework causation has stagnated. Factors identified decades are still being identified, yet rework remains a prevailing and chromic problem. Tools such as questionnaire surveys used to identify and rank a list of single causal factors have contributed to this stagnation because they provide no explanation of causality; thus, it is recommendation a moratorium being placed on such studies. Moreover, recent research has discounted the notion that rework causes arise from a chain of causal conditions and a seemingly counterfactual in nature with pathogens providing being preemptive. The limitations of assuming counterfactual causation are identified and thus need to be accommodated in a theory that can explain rework causation. 
The braiding of an epistemological-based notion of sensemaking with probabilistic causation accommodates both the qualitative and quantitative aspects of rework causation needed to develop a balanced and robust theory. Future research should place emphasis on constructing a theory that can accommodate nomologically different contexts but also be generalizable and parsimonious. This is and will continue to be a challenge, but this paper provides the valuable insights needed to move research forward in rework causation.

\section{Acknowledgements}

The authors would like to thank the Australian Research Council (DP130103018) for the funding which enabled the ideas and empirical research drawn upon to be presented in this paper.

\section{References}

Abdul-Rahman, H. (1995). The cost of non-conformance during a highway project: A case study. Construction Management and Economics, 13, pp.23-32

Ackermann, F., Eden, C., and Williams, T. (1997). Modeling for litigation: mixing qualitative and quantitative approaches. Interfaces, 27(2), pp.48-65.

Ackermann, F. Eden, C., and Cropper, S. (1992). Getting started with cognitive mapping. Proceedings of the $7^{\text {th }}$ Young OR Conference, $13^{\text {th }}-15^{\text {th }}$ April, University of Warwick, UK (Available at www.banxia.com, accessed $11^{\text {th }}$ February, 2015)

Ackermann, F., and Eden, C. (2005). Using causal mapping with group support systems to elicit an understanding of failure in complex projects: some implications for organizational research. Group Decision and Negotiation, 14(5),pp.355-376

Ackermann, F. (2012). Problem structuring methods 'in the Dock': Arguing the case for soft OR European Journal of Operational Research, 219(3), pp.652-658.

Aiyetan, A.O. (2013). Causes of rework on building construction projects in Nigeria. Journal of Construction Project Management and Innovation 12(3), pp.1-15

Aljassmi, H. and Han, S. (2013). Analysis of causes of construction defects using fault trees and risk importance measures. ASCE Journal of Construction Engineering and Management 139(7), pp. 870-880

Balke, A.A. (1995). Probabilistic Counterfactuals: Semantics, Computation, and Applications. University of California, Los Angeles

Barber, P., Sheath, D., Tomkins, C., and Graves, A. (2000). The cost of quality failures in major civil engineering projects. International Journal of Quality and Reliability Management, 17(4/5), 479-492.

Bell, J. (2004) Causation and causal conditions. In Proceedings of the $9^{\text {th }}$ International Conference on the Principles of Knowledge Representation and Reasoning, In Dubios, D. et al. (Eds.) AAAI Press, pp.2-11. 
Bell, J. (2007). Natural events. Journal of Artificial Intelligence Research, 30, pp.361-412.

Burati, J. L., Farrington, J. J., and Ledbetter, W. B. (1992). Causes of quality deviations in design and construction. Journal of Construction Engineering and Management, 118(1), pp.34-49. Busby, J.S. (2001). Error and distributed cognition in design. Design Studies, 22, pp. 233-254. Byrne, R.M.J. (2005). The Rational Imagination: How People Create Counterfactual Alternatives to Reality. MIT Press. Cambridge, Massachusetts:

Cavender, N.M and Kahne, H. (2010). Logic and Contemporary Rhetoric: The Use of Reason in Everyday Life. $11^{\text {th }}$ Edition, Wadsworth, Belmont, CA

Construction Industry Development Agency (1995). Measuring Up or Muddling Through: Best Practice in the Australian Non-Residential Construction Industry, Construction Industry Development Agency and Masters Builders Australia Sydney, Australia, pp. 59-63.

Cooper, K.G. (1993a). The rework cycle: why projects are mismanaged. PM Network Magazine, February, p.5-7.

Cooper, K.G. (1993b). The rework cycle: Benchmarks for the project manager. Project Management Journal, 24(1), pp.17-21

Dekker, S. W. A. (2002). Reconstructing the human contribution to accidents: The new view of human error and performance. Journal of Safety Research, 33 (3), 371-385.

Dekker, S.W.A. (2006). The Field Guide to Understanding Human Error. Farnham, Ashgate

Damer, T. E.(1995). Attacking Faulty Reasoning: A Practical Guide to Fallacy-Free Arguments. ( $3^{\text {rd }}$. Ed.). Wadsworth Publishing. Belmont, CA, p. 131.

Di Tillio, A., Gilboa, I. and Samuelson, L (2012). The predictive role of counterfactuals. Theory and Decision, 73 (1), pp.NC. <10.1007/s11238-011-9263-6>.

Ford, D.N. and Sterman, J.D. (2003). The lair's club: concealing rework in concurrent development. Concurrent Engineering: Research and Applications, 11(3), pp.211-219.

Frege, G. (1879). Concept Notation, the Formal Language of the Pure Thought like that of Arithmetics. In German, Begriffsschrift: eine der arithmetischen nachgebildete Formelsprache des reinen Denkens. Halle,

Goodman, N.D., Ullman, T. and Tenebaum, J.B. (2011). Learning a theory of causality. Psychological Review, 118(1), pp.110-119

Josephson, P.-E., Larrson, B., and Li, H. (2002). Illustrative benchmarking rework and rework costs in the Swedish construction industry. ASCE Journal of Management in Engineering, 18(2), pp.76-83.

Han, S., Love, P.E.D., and Pena-Mora, F. (2013). A system dynamics model for assessing the impacts of design errors in construction projects. Mathematical and Computer Modelling, 57(9/10), pp. 2044-2053.

Hausmann, D.M (2010). Proabilistic Causality and Causal Generalizations. In E.Eells and J.H. Fetzer (Eds.) The Place of Proability in Science. Boston Studies in the Philosophy of Science 284, Springer Science and Business Media. B.V. 
Hitchcock, C. (2001). The intransitivity of causation revealed in equations and graphs. Journal of Philosophy, 98, pp. 273-99.

Hitchcock, C. (2012). Probabilistic Causation. The Stanford Encyclopedia of Philosophy. Zalta, E.N. (Ed.), Winter, Available at www://plato.stanford.edu/archives/win2012/entries/causation-probabilistic/>, Accessed $28^{\text {th }}$ February, 2015)

Hollnagel, E. (2004). Barriers and Accident Prevention. Farnham, Ashgate, UK

Hwang, B.-G., Thomas, S.R., Haas, C.T., and Caldas, C.H. (2009). Measuring the impact of rework on construction cost performance. ASCE Journal of Construction Engineering and Management, 135(3), pp.187-198.

Hwang, B-G., Zhao, X., and Goh, K.J. (2014), Investigating the client-related rework in building projects: The case of Singapore. International Journal of Project Management, 32(4), pp.698-708

Janis, I.L., and Mann, L. (1977). Decision-Making: A Psychological Analysis of Conflict, Choice and Commitment. Free Press, New York

Jingmond, M., and Ågren, R. (2015). Unravelling causes of defects in construction. Construction Innovation, 15(2) pp

Kahneman, D., and Tversky, A. (1974). Judgment under Uncertainty: Heuristics and biases Science, 185, (4157) pp. 1124-1131.

Kahneman, D., and Tversky, A. (1982). Judgments of and by representativeness. In D. Kahneman, P. Slovic., and A. Tversky. (Eds.). Judgment Under Uncertainty: Heuristics and Biases. Cambridge University Press, Cambridge, UK

Kahneman, D., and Tversky, A. (1983). Extension versus intuitive reasoning: the conjunction fallacy in probability judgment. Psychological Review, 90(4), pp.293-315.

Kakitahi, J.M., Alinaitwe, H. M. Landin, A., and Rodrigues, M.J.A. (2014). Comparison of construction related rework in Uganda and Mozambique. Journal of Construction Project Management and Innovation, 4(1), pp.770-781

Kelly, G.A.(1955).The Psychology of Personal Constructs. Norton, New York

Li, Y. and Taylor, T. (2014). Modeling the impact of design rework on transportation infrastructure construction project performance. ASCE Journal of Construction Engineering and Management, 140(9), pp.

Lewis, D. (1973). Causation. Journal of Philosophy, 60, pp. 17-25, 1973.

Lewis, D. (2000). Causation as influence. Journal of Philosophy, 97, pp.182-197.

Lewis, D. (2004).Void and Object. In. Collins, J., Hall, E., and Paul, L., 2004. Causation and Counterfactuals, Cambridge, MIT Press, Massachusetts, pp. 277-90.

Love, P.E.D., Li, H., and Mandal, P. (1999). Rework: a symptom of a dysfunctional supply-chain. European Journal of Purchasing and Supply Management, 5(1), pp.1-11.

Love, P.E.D., and Li, H. (2000). Quantifying the causes and costs of rework in construction. Construction Management and Economics, 18(4), pp.479-490. 
Love, P.E.D. (2002a). Influence of project type and procurement method on rework costs in building construction projects. ASCE Journal of Construction Engineering and Management, 128(1), pp.18-29.

Love, P.E.D. (2002b). Auditing the indirect consequences of rework in construction: A case based approach. Managerial Auditing Journal, 17(3), pp.138-146.

Love, P.E.D., Holt, G.D., and Li, H. (2002). Triangulation in construction management research. Engineering, Construction and Architectural Management, 9(4), pp. 294-303.

Love, P.E.D., and Josephson, P-E. (2004). Role of the error-recovery process in projects. ASCE Journal of Management in Engineering, 20(2), pp.70-79.

Love, P.E.D., and Edwards, D., (2004). Determinants of rework in construction projects. Engineering, Construction and Architectural Management, 11(4) pp. 259-274.

Love, P.E.D., Irani, Z., and Edwards, D.J. (2004). A rework reduction model for construction projects. IEEE Transactions on Engineering Management, 51(4), pp.426-440.

Love, P.E.D., Edwards, D.J., Smith, J., and Walker, D.H.T. (2009a). Congruence or divergence? A path model of rework in building and civil engineering projects. ASCE Journal of Performance of Constructed Facilities, 23(6), pp. 480-488.

Love, P.E.D. Edwards, D.J., Irani. Z., and Walker, D.H.T. (2009b). Project pathogens: The anatomy of omission errors in construction and resource engineering projects. IEEE Transactions on Engineering Management 56(3), pp.425-435.

Love, P.E.D., Edwards, D.J. Han, S., and Goh, Y.M. (2011a). Design error reduction: Toward the effective utilization of building information modelling. Research in Engineering Design, 22(3), pp.173-187.

Love, P.E.D., Cheung, S.O., Irani, Z and Davis, P.R. (2011b). Causal discovery and inference of project disputes. IEEE Transactions on Engineering Management 58(3), pp.400 - 411.

Love, P.E.D., Lopez, R. Edwards, D.J. and Goh, Y. (2012a). Systemic modelling of design errors in social infrastructure projects. Accident Analysis and Prevention, 48, pp. 100-110.

Love, P.E.D, Edwards, D.J., and Irani, Z. (2012b). Moving beyond optimism bias and strategic misrepresentation: An explanation for social infrastructure project cost overruns. IEEE Transactions on Engineering Management 59(4), pp. 560 - 571.

Love, P.E.D. and Sing, C-P. (2013). Determining the probability distribution of rework Costs in construction and engineering projects. Structure and Infrastructure Engineering, 9(11), pp. 1136-1148.

Love, P.E.D. Ackermann, F., Smith, J. and Edwards, D.J. (2015a). Reconceiving rework causation in hydrocarbon projects. International Journal of Production Economics (Under review)

Love, P.E.D., Ackermann, F., Carey, B., Parke, M., and Morrison, J. (2015b). Learning alliance: rework prevention in water infrastructure projects. ASCE Journal of Construction Engineering and Management (In Press) 
Love, P.E.D Teo, P Ackermann, F., and Morrison, J. (2015bc). From individual to collective learning: enacting rework prevention in a program water infrastructure alliance. ASCE Journal of Construction Engineering and Management (In Press)

Lyneis, J.M. and Ford, D.N. (2007). System dynamics applied to project management: a survey, assessment, and directions for future research. System Dynamics Review, 23, pp.157-189,

Menzies, P. (1989). Probabilistic causation and causal processes: A critique of Lewis, Philosophy of Science, 56, pp.642-663.

Menzies, P. (1996). Probabilistic causation and the pre-emption problem. Mind, 105, pp.85-117.

Menzies, P. (1999). Intrinsic versus Extrinsic Conceptions of Causation. In Sankey, H. (Ed.), Causation and Laws of Nature, Kluwer Academic Publishers, pp. 313-29.

Menzies, P. (2014). Counterfactual Theories of Causation, The Stanford Encyclopedia of Philosophy Edward N. Zalta, Z.N (Ed.), Sping, Available at: www.stanford.edu/archives/spr2014/entries/causation-counterfactual, Accessed 28th February, 2015)

Miller, G. and Johnson-Laird, P.N. (1976). Language and Perception. Cambridge University Press, Cambridge.

Noordhof, P.(1999). Probabilistic causation, preemption and counterfactuals. Mind, 108, pp.95125

Paul, L.A., (2009). Counterfactual Theories of Causation. In Beebee, H. Hitchcock,C., and Peter Menzies, P. (Ed), Handbook of Causation. Oxford Handbooks on Philosphy, Oxford University Press

Pearl, J. (2000). Causality: Models, Reasoning and Inference. Cambridge University Press, Cambridge

Robinson-Fayek, A., Dissanayake, M., and Campero, O. (2004). Developing a standard methodology for measuring and classifying construction fieldwork. Canadian Journal of Civil Engineering, 31(6), pp.1077-1089.

Rogge, D.F., Cogliser, C., Alaman, H., and McCormack, S. (2001). An Investigation into Field Rework in Industrial Construction. Report No.RR153-11, Construction Industry Institute, Austin, Texas.

Rodigues, A., and Bowers, J. (1996). The role of system dynamics in project management. International Journal of Project Management, 14(4), pp.213-220.

Roese, N. (1997). Counterfactual thinking. Psychological Bulletin, 121(1), pp.133-148.

Roese, N.J. and Olson, J.M. (1995). What Might Have Been: The Social Psychology of Counterfactual Thinking. Erlbaum, New Jersey:

Roth, G., and Kliener, A. (1996). The Learning Initiative at AutoCo Epiloson Program. 19911994. Center for Organizational Learning, Sloan School of Management, Massachusetts Institute of Technology, Cambridge, MA

Russell, B. (1913). On the notion of cause. Proceedings of the Aristotelian Society, 13, pp.1-26.

Salmon, W.C. (1998). Causality and explanation. Oxford University Press, Oxford

Schaffer, J. (2000). Trumping Preemption. Journal of Philosophy, 9, pp.165-81. 
Schacter, D.L., Benoit, R.G., De Brigard, F., and Szpunar, K.K (2013). Episodic Future Thinking and Episodic Counterfactual Thinking: Intersections Between Memory and Decisions. Neurobiology of Learning and Memory, pii: S1074-7427(13)00263-3

Shaw, B.M. (1981). The escalation of commitment to a course of action. Academy of Management Review, 6, pp. 274-297.

Taggart, M, Koskeal, L., and O'Rourke, J. (2014). The role of the supply chain in the elimination and reduction of construction rework and defects: an action research approach. Construction Management and Economics, 32,(7/8), pp.829-842

Taylor, T. and Ford, D.N. (2006). Tipping point failure and robustness in single development projects. System Dynamics Review, 22(1), pp. 51-71.

Taylor, T. and Ford, D.N (2008). Managing tipping point dynamics in complex construction projects. ASCE Journal of Construction Engineering and Management, 134(6), pp. 421-431.

Tenenbaum, J. B., and Griffiths, T. L. (2003). Theory-based causal induction. In S. Becker, S. Thrun, and K. Obermayer (Eds.). Advances in neural information processing systems, Vol. 15, pp. 35-42, MIT Press, Cambridge, MA:

Tombesi, P. (2000). Modelling the dynamics of design error induced rework in construction: comment. Construction Management and Economics, 18(7), pp. 727-732.

Tversky, B. (1993). Cognitive maps, cognitive collages, and spatial mental models In Spatial Information Theory A Theoretical Basis for GIS. Lecture Notes in Computer Science Volume 716, 1993, pp 14-24

Weick, K.E. (2001). Making Sense of the Organization. Blackwell Publishing, Malden, MA,

Williams, T.M., Ackermann, F., and Eden, C. (2003). Structuring a delay and disruption claim: An application of cause-mapping and system dynamics. European Journal of Operational Research, 148(1), pp.192-204.

Williamson, J. (2006a). Causal pluralism versus epistmic causality. Philosohica, 77, pp.259-276.

Williamson, J. (2006b). Dispositional versus epistemic causality. Minds and Machines, 16, pp.259-276.

Williamson, J. (2009). Probabilistic Theories of Causality. In Beebee, H. Hitchcock,C., and Peter Menzies, P. (Ed), Handbook of Causation. Oxford Handbooks on Philosphy, Oxford University Press pp. 185-212

Wold, H. (1954). Causality and econometrics. Econometrica, 22(2), pp.162-177

Ye, G., Jin, Z., Xia, B., and Skitmore, M. (2014). Analyzing causes for reworks in construction projects in China. ASCE Journal of Management Engineering, 10.1061/(ASCE)ME.1943$5479.0000347,04014097$. 